https://dx.doi.org/10.4314/ijs.v20i2.23

Ife Journal of Science vol. 20, no. 2 (2018)

\title{
AB INITIO STUDY OF TRANSITION METALS IMPURITIES AND STABILITY OF COMPLEXES IN GERMANIUM (Ge)
}

\author{
Igumbor, E..$^{{ }^{*}}$, Omotoso, E. ${ }^{2^{*}}$, Khaleed, A. A. ${ }^{3}$, Taleatu, B. A. ${ }^{2}$ \\ ${ }^{1}$ Department of Mathematical and Physical Sciences, Samuel Adegboyega University, Edo, Nigeria \\ ${ }^{2}$ Department of Physics and Engineering Physics, Obafemi Awolowo University, Ile-Ife, Nigeria \\ ${ }^{3}$ Department of Physics, Ahmadu Bello University, Zaria, Nigeria \\ Corresponding author e-mail address: omotoeze@gmail.com; elgumuk@gmail.com \\ (Received: 18th December, 2017; Accepted: 11th July, 2018)
}

\section{ABSTRACT}

\begin{abstract}
By means of density functional theory, we present results of an ab initio calculation of vacancy-interstitial complexes $\left(\mathrm{T}_{\mathrm{Ge}}-\mathrm{V}_{n \mathrm{Ge}} \mathrm{I}_{\mathrm{T}}\right.$, for $n=1,2,3$ and $\mathrm{T}$ : Cr, Mo, W, Mn and Fe) in Ge. The projector-augmented wave pseudo-potential within the generalized gradient approximation was used for all calculations. Structural properties and formation energies of the $\mathrm{T}_{\mathrm{Ge}}-\mathrm{V}_{n \mathrm{Ge}} \mathrm{I}_{\mathrm{T}}$ for the neutral charge state were obtained. Our results show that under equilibrium conditions, vacancy-interstitial complex $\mathrm{T}_{\mathrm{Ge}}-\mathrm{V}_{\mu \mathrm{Ge}} \mathrm{I}_{\mathrm{T}}$ formed with formation energies not higher than $-1.00 \mathrm{eV}$. The formation energy result showed that the $\mathrm{T}_{\mathrm{Ge}}-\mathrm{V}_{n \mathrm{Ge}} \mathrm{I}_{\mathrm{T}}$ is energetically more favourable for $n=1$ and 2 than $n=3$. The stabilities of the vacancy-interstitial complexes were obtained from their binding energies. For all $\mathrm{T}$, the binding energies of the $\mathrm{T}_{\mathrm{Ge}}-\mathrm{V}_{\mathrm{Ge}} \mathrm{I}_{\mathrm{T}}$ are stable. For the $\mathrm{T}_{\mathrm{Ge}}-\mathrm{V}_{2 \mathrm{Ge}} \mathrm{I}_{\mathrm{T}}$ and $\mathrm{T}_{\mathrm{Ge}}-\mathrm{V}_{3 \mathrm{Ge}} \mathrm{I}_{\mathrm{T}}$, their binding energies lie between 1.79 and $6.10 \mathrm{eV}$ and defect complexes are stable.
\end{abstract}

Keywords: Density functional theory, vacancy-interstitial, formation energy, impurities

\section{INTRODUCTION}

Due to low level of impurity and high electronhole mobility of germanium (Ge), its application in semiconductor material technology has been promising and attracting attention (Claeys and Simoen, 2011; Chui et al., 2003). Several studies on point defects in Ge have been studied either by experimental technique or theoretical modelling (Nyamere et al., 2008; Fage-Pedersen et al., 2000). Recently, it was revealed that some impurities form as complexes in Ge (Chroneos et al., 2007; Chroneos and Bracht, 2014). Chroneos et al., 1999, by using the generalized gradient approximation (GGA), predicted that except for boron (which mediate fast through interstitial in Ge), the group III impurities atoms are stable and formed vacancy-complexes in Ge. However, boron defect in $\mathrm{Ge}$ is found to be stable in the interstitialcomplex. As a result, interest has been rekindled to find out if other impurities apart from interstitialcomplexes are stable in Ge. Study on transition metal vacancy-interstitial complexes in silicon (Si) reveals that iron $(\mathrm{Fe})$, which is one of the known detrimental metal impurities, causes depletion of charge migration in metal oxide semiconductor devices and thus acts as an effective minority carrier (Chroneos, 2010). Other studies on transition metal defects in $\mathrm{Si}$ and other semiconducting materials have been reported in literature (Istratoy and Weber, 2002). For instance, Derlet et al., 2007 reported that the binding energy between the second nearest neighbour vacancies in ferromagnetic bcc Fe is more favourable than those of the nearest neighbour configuration. However, to the knowledge of the authors, transition metals (such as $\mathrm{Cr}, \mathrm{Mo}, \mathrm{W}, \mathrm{Mn}$ and $\mathrm{Fe}$ ) related vacancy and interstitial-complexes in $\mathrm{Ge}$ have not been reported. Therefore, this study aims at investigating the structure and energetics of "Frenkel like" vacancy-interstitial complexes $\left(\mathrm{T}_{\mathrm{Ge}}{ }^{-}\right.$ $\mathrm{V}_{\mathrm{nGe}} \mathrm{I}_{\mathrm{T}}$, for $\left.n=1,2,3\right)$ in Ge. In addition, this study provides a frontier insight for the proper understanding of $\mathrm{T}_{\mathrm{Ge}}-\mathrm{V}_{\mathrm{nGe}} \mathrm{I}_{\mathrm{T}}$ complexes in Ge. By means of density functional theory (DFT), we present an $a b$ initio calculation of vacancyinterstitial complexes $\left(\mathrm{T}_{\mathrm{Ge}}-\mathrm{V}_{\mathrm{nGe}} \mathrm{I}_{\mathrm{T}}\right.$, for $n=1,2,3$ and T: Cr, Mo, W, Mn and Fe) in Ge. Our calculations employed the projector-augmented wave (PAW) pseudopotential within the generalized gradient approximation (GGA). Structural properties and formation energies of the $\mathrm{T}_{\mathrm{Ge}}-\mathrm{V}_{\mathrm{nGe}} \mathrm{I}_{\mathrm{T}}$ for the neutral charge state were obtained. The binding energies of the $\mathrm{T}_{\mathrm{Ge}}-\mathrm{V}_{\mathrm{nGe}} \mathrm{I}_{\mathrm{T}}$ complexes were predicted.

\section{COMPUTATIONAL DETAILS}

In this report, DFT electronic structure 
calculations were performed using the Vienna ab initio Simulation Package (VASP) (Kresse and Furthmu"ller, 1996). The projector-augmented wave (PAW) method, as implemented in the VASP code was used to separate the inner core electrons from the chemically active valence electrons (Kresse and Joubert, 1999; Kresse and Furthmu"ller, 1996; Bl"ochl, 1994). All calculations were carried out using the generalized gradient approximation (GGA), functional of Perdew, Burke, and Ernzerhof (PBE) Perdewet al., 1996). DFT calculations based on the local density approximation (LDA) and GGA results have shown to underestimate the band gap properties and formation energies of most defects in $\mathrm{Ge}$ (Déak et al., 2010; Igumbor et al., 2016; Igumbor et al., 2015; Igumbor and Meyer, 2016). However, previous studies have demonstrated the efficacy of using the GGA exchange correlation functional to predict the binding energies of defects in $\mathrm{Ge}$ by comparison with other experimental study (Chroneos et al., 2007). In addition, in this report, we focused only on the geometric structures of the complexes and binding energies which are determined from differences in defects formation energies. As a result, we expect that our results will be less sensitive to the exchange-correlation function.

We used a 64-atom super cell as the pristine. For the defects, a number of vacancies were created, and a transition metal atom was substituted in place of $\mathrm{Ge}$ atom. In addition, a transition metal atom was placed in an interstitial site in the 64atom supercell. Both for the pristine and the defects, we used $2^{3}$ Monkhorst-Pack special kpoints Brillouin zone sampling scheme, achieving convergence of the total energy by setting the energy cut-off of the wave function expansion to $400 \mathrm{eV}$. In all the calculations, the structural optimization continued until both the total energy and forces were less than $10^{-5} \mathrm{eV}$ and $0.01 \mathrm{eV} /{ }^{\circ} \mathrm{A}$, respectively. Since the energy of formation of a system is strongly dependent on the spin-orbit coupling (SOC) due to the presence of relativistic effects in heavy atomic systems, the scalar relativistic effect has been taken into consideration by incorporating into the PAW potential the mass-velocity and Darwin correction terms. In addition to the scalar relativistic effect that was taken into account, spin orbit coupling was also taken into account for all calculations. To calculate the formation energy $\left(E^{f}\right)$ of a defect, we calculated the total energy $E(d)$ for a supercell containing the optimized defect $\mathrm{d}$. The defect formation energy $E^{f}(d)$ is given as (Zhang and Northruo, 1991; Christoph et al., 2014)

$$
E^{f}(d)=E(d)-E(\text { pure })+\sum_{i} \Delta(n)
$$

where $E$ (pure) is the total energy of a supercell without a defect, $\Delta((\quad(\Delta(\mathrm{n})<$, when an atom is added and $\Delta(\mathrm{n})>$ when an atom is removed) is the difference in the number of constituent atoms of type $i$ between the pristine super cell and the super cell containing the defect, and $\mu_{i}$ is the chemical potential of type $i$ th atom. The binding energy $E_{b}$ which is defined as the energy required to split up defect cluster into well separated noninteracting defects is given as (Zolloet al., 2004)

$E_{b}=E_{\left(V_{G e}\right)}^{f}+E_{\left(T_{G e}\right)}^{f}+E_{\left(l_{T}\right)}^{f}-E_{(\text {defect-complex })}^{f}$

where the $E_{(v)}^{f}, E_{(\mathrm{T},}^{f}, E$ and $E_{(\text {defect-complex })}^{f}$ are the

formation energies of $\mathrm{V}_{\mathrm{Ge}}, \mathrm{T}_{\mathrm{Ge}}, \mathrm{I}_{\mathrm{T}}$ and $\mathrm{T}_{\mathrm{Ge}}-\mathrm{V}_{\mathrm{nGe}} \mathrm{I}_{\mathrm{T}}$, respectively. Eq. 2 could be interpreted as the energy released from the bonded structure with respect to the isolated components.

\section{RESULTS}

\section{Structuralproperties}

The geometric structures of the relaxed $\mathrm{T}_{\mathrm{Ge}}-\mathrm{V}_{\mathrm{nGe}} \mathrm{I}_{\mathrm{T}}$ (where $T_{G e}$ is a transition metal substitutional impurity in $\mathrm{Ge}, \mathrm{V}_{\mathrm{Ge}}$ and $\mathrm{I}_{\mathrm{T}}$ are Ge vacancy and $\mathrm{T}$ interstitial, respectively) are shown in Fig.1. Fig.1a represents the relaxed geometric structure of a 64atom $\mathrm{Ge}$ supercell. While Fig.1b represents the relaxed geometric structure of the $\mathrm{T}_{\mathrm{Ge}}-\mathrm{V}_{\mathrm{Ge}} \mathrm{I}_{\mathrm{T}}$, Figs.1c and 1d show the relaxed geometric structures of $\mathrm{T}_{\mathrm{Ge}}-\mathrm{V}_{2 \mathrm{Ge}} \mathrm{I}_{\mathrm{T}}$ and $\mathrm{T}_{\mathrm{Ge}}-\mathrm{V}_{3 \mathrm{Ge}} \mathrm{I}_{\mathrm{T}}$, respectively. 


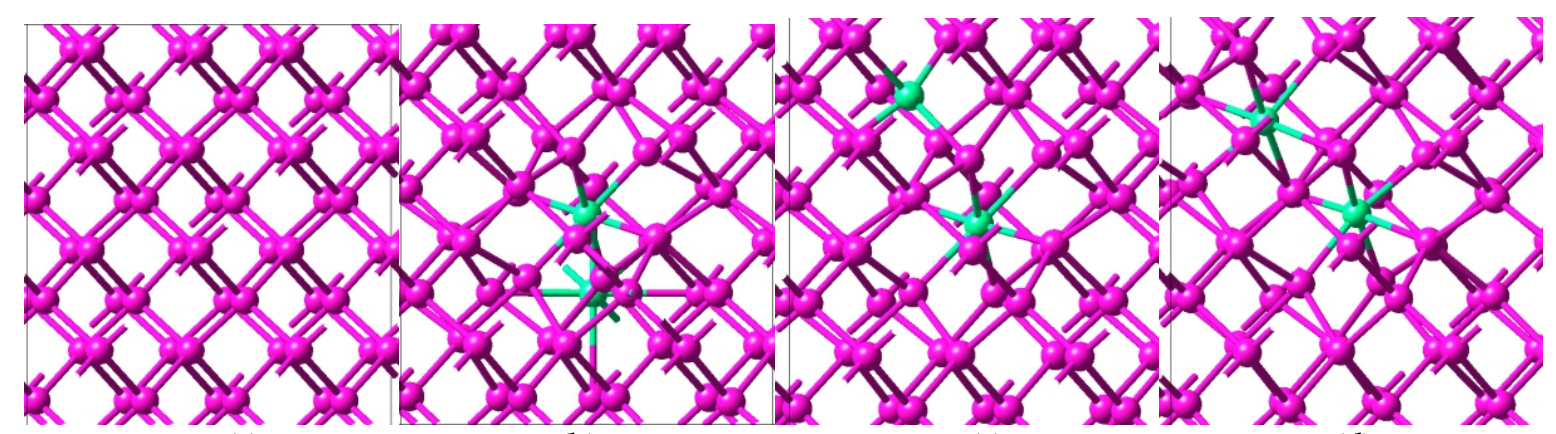

(a)

(b)

(c)

(d)

Fig. 1. The relaxed geometric structures of $\mathrm{Ge}$ and $\mathrm{T}_{\mathrm{Ge}}-\mathrm{V}_{n \mathrm{Ge}} \mathrm{I}_{\mathrm{T}}$ (a) a 64-atom Ge supercell;

(b) $\mathrm{T}_{\mathrm{Ge}}-\mathrm{V}_{\mathrm{Ge}} \mathrm{I}_{\mathrm{T}}$; (c) $\mathrm{T}{ }_{\mathrm{Ge}}-\mathrm{V}_{2 \mathrm{Ge}} \mathrm{I}_{\mathrm{T}}$ and (d) $\mathrm{T}{ }_{\mathrm{Ge}}-\mathrm{V}_{3 \mathrm{Ge}} \mathrm{I}_{\mathrm{T}}$. The colour ato $\mathrm{ms}$ are the $\mathrm{T}$ impurities introduced into a 64-atom supercell of Ge.

The predicted average bond lengths separation between $\mathrm{T}$ and its nearest neighbours Ge atoms are shown in Table 1. Our theoretical calculation of the bond length of Ge-Ge atoms is $2.45 \AA$, which is in good agreement with experimental and other theoretical results reported in literature (Singh, 1968; Chroneos et al., 2007). For the $\mathrm{T}_{\mathrm{Ge}^{-}}$ $\mathrm{V}_{n \mathrm{Ge}} \mathrm{I}_{\mathrm{T}}$, in all $\mathrm{T}$, the differences between the bond length $(\Delta \mathrm{x})$ before and after geometric relaxation are between 0.25 and $0.09 \AA$. For the $\mathrm{T}_{\mathrm{Ge}}-\mathrm{V}_{\mathrm{Ge}} \mathrm{I}_{\mathrm{T}}$, the $\mathrm{Fe}$ and $\mathrm{Cr}$ related complexes experience more strain in their bond length than the other $T$ related complexes. The $\mathrm{Fe}$ and $\mathrm{Cr}$ related complexes have $\Delta_{a}$ of 0.16 and $0.24 \AA$, respectively. While for the $\mathrm{T}_{\mathrm{Ge}}-\mathrm{V}_{2 \mathrm{Ge}} \mathrm{I}_{\mathrm{T}}$, Mo and Fe related defects experience

Table 1. The predicted average bond lengths of T and its nearest neighbour Ge atoms distance in $\AA, \beta$ and $a$, are the T-Ge atoms bond length before and after geometric relaxations, respectively. The $\Delta_{x}$ is the difference between $\beta$ and $a$, for $x=a, b, c$.

\begin{tabular}{cccc|ccc|ccc}
\hline Defect(T) & \multicolumn{3}{c|}{$\mathrm{T}_{\mathrm{Ge}}-\mathrm{V}_{\mathrm{Ge}}$} & \multicolumn{3}{|c|}{$\mathrm{T}_{\mathrm{Ge}}-\mathrm{V}_{2 \mathrm{Ge}} \mathrm{I}_{\mathrm{T}}$} & \multicolumn{3}{|c}{$\mathrm{T}_{\mathrm{Ge}}-\mathrm{V}_{3 \mathrm{Ge}} \mathrm{I}_{\mathrm{T}}$} \\
\hline & $\beta$ & $a$ & $\Delta_{a}$ & $\beta$ & $a$ & $\Delta_{b}$ & $B$ & $a$ & $\Delta_{c}$ \\
\hline $\mathrm{Cr}$ & 2.46 & 2.70 & 0.24 & 2.69 & 2.53 & 0.16 & 2.47 & 2.68 & 0.19 \\
$\mathrm{Mo}$ & 2.46 & 2.56 & 0.10 & 2.69 & 2.50 & 0.19 & 2.47 & 2.38 & 0.07 \\
$\mathrm{~W}$ & 2.45 & 2.54 & 0.09 & 2.68 & 2.53 & 0.13 & 2.44 & 2.47 & 0.03 \\
$\mathrm{Mn}$ & 2.45 & 2.53 & 0.08 & 2.68 & 2.58 & 0.10 & 2.44 & 2.58 & 0.14 \\
$\mathrm{Fe}$ & 2.45 & 2.29 & 0.16 & 2.68 & 2.43 & 0.25 & 2.45 & 2.29 & 0.16 \\
\hline
\end{tabular}

larger strain in the bond length than others, the $\mathrm{T}_{\mathrm{Ge}}-\mathrm{V}_{3 \mathrm{Ge}} \mathrm{I}_{\mathrm{T}}$ follows the same trend as the $\mathrm{T}_{\mathrm{Ge}}-\mathrm{V}_{\mathrm{Ge}} \mathrm{I}_{\mathrm{T}}$ with $\Delta_{c}$ of 0.16 and $0.19 \AA$, for the $\mathrm{Fe}$ and $\mathrm{Cr}$ related complexes, respectively. Interestingly we found that while for all $\mathrm{T}$ after geometric relaxation, the average $\mathrm{T}-\mathrm{Ge}$ bond lengths increases for the case of the $\mathrm{T}_{\mathrm{Ge}}-\mathrm{V}_{\mathrm{Ge}} \mathrm{I}_{\mathrm{T}}$, but for the case of the $\mathrm{T}_{\mathrm{Ge}}-\mathrm{V}_{\mathrm{Ge}} \mathrm{I}_{\mathrm{T}}$ it reduces.

Formation energy of the $T_{\mathrm{Ge}}-V_{n \mathrm{Ge}} I_{\mathrm{T}}$ The result of the calculated energy of formation for the various complexes are displayed in Table 2.
Fig. 2 represents the plot of formation energies as a function of the transition metal. Since we are investigating the stability of the complexes, we have limited our calculations only to the neutral charge state. The formation energies of $\mathrm{T}_{\mathrm{Ge}}-\mathrm{V}_{\mathrm{Ge}} \mathrm{I}_{\mathrm{T}}$ for the $\mathrm{Mn}, \mathrm{Mo}, \mathrm{Cr}, \mathrm{W}$ and $\mathrm{Fe}$ impurities are between -8.74 and $-2.85 \mathrm{eV}$. The $\mathrm{M}_{\mathrm{nGe}}-\mathrm{V}_{\mathrm{Ge}} \mathrm{I}_{\mathrm{Mn}}$ has the lowest formation energy of $-8.74 \mathrm{eV}$. The order of the sequence of formation energies is $\mathrm{Mn}<\mathrm{W}<\mathrm{Mo}<\mathrm{Cr}<\mathrm{Fe}$, as shown in Fig. 2. For all $\mathrm{T}$, the formation energies of the $\mathrm{T}_{\mathrm{Ge}}-\mathrm{V}_{2 \mathrm{Ge}} \mathrm{I}_{\mathrm{T}}$ are lower than that of the $\mathrm{T}_{\mathrm{Ge}}-\mathrm{V}_{\mathrm{Ge}} \mathrm{I}_{\mathrm{T}}$. For the $\mathrm{T}_{\mathrm{Ge}}-\mathrm{V}_{2 \mathrm{Ge}} \mathrm{I}_{\mathrm{T}}$, the 
$\mathrm{Mn}_{\mathrm{Ge}}-\mathrm{V}_{2 \mathrm{Ge}} \mathrm{I}_{\mathrm{Mn}}$ has the lowest formation energies of $-10.29 \mathrm{eV}$. For the $\mathrm{T}_{\mathrm{Ge}}-\mathrm{V}_{2 \mathrm{Ge}} \mathrm{I}_{\mathrm{T}}$, as it is observed for the case of the $\mathrm{T}_{\mathrm{Ge}}-\mathrm{V}_{\mathrm{Ge}} \mathrm{I}_{\mathrm{T}}$, Fe related defects have the highest formation energies. For the $\mathrm{T}_{\mathrm{Ge}}-\mathrm{V}_{3 \mathrm{Ge}_{\mathrm{T}}} \mathrm{I}_{\mathrm{T}}$, the formation energies are between -9.60 and $-4.63 \mathrm{eV}$. The sequence of the formation energy is the same as that of the $\mathrm{T}_{\mathrm{Ge}}-\mathrm{V}_{\mathrm{Ge}} \mathrm{I}_{\mathrm{T}}$. From the results of the formation energy, it is obvious that for all $\mathrm{T}$ and $n$, the $\mathrm{Mn}$ related defect under equilibrium condition is energetically the most favourable and the $\mathrm{Fe}$ and the $\mathrm{Cr}$ related defects are energetically less favourable. For the $\mathrm{T}_{\mathrm{Ge}^{-}}$ $\mathrm{V}_{3 \mathrm{Ge}} \mathrm{I}_{\mathrm{T}}, \mathrm{T}_{\mathrm{Ge}}-\mathrm{V}_{2 \mathrm{Ge}} \mathrm{I}_{\mathrm{T}}$ and $\mathrm{T}_{\mathrm{Ge}}-\mathrm{V}_{\mathrm{Ge}} \mathrm{I}_{\mathrm{T}}$, except for $\mathrm{Cr}$ which is energetically most favourable in $\mathrm{T}_{\mathrm{Ge}^{-}}$ $\mathrm{V}_{\mathrm{Ge}} \mathrm{I}_{\mathrm{T}}$, the Mo, W, Mn and Fe are energetically most favourable in the $\mathrm{T}_{\mathrm{Ge}}-\mathrm{V}_{2 \mathrm{Ge}} \mathrm{I}_{\mathrm{T}}$. The difference in formation energies could be as a result of the level or amount of strain experienced by the bond lengths when defect was introduced into the supercell.

Table 2. Predicted formation energies $\mathrm{E}_{f}$ in $\mathrm{eV}$ of $\mathrm{T}_{\mathrm{Ge}}-\mathrm{V}_{n \mathrm{Ge}} \mathrm{I}_{\mathrm{T}}$ (for $n=1,2$, and 3) complexes in Ge. The lowest formation energy for a transition metal in each complexis written in bold.

\begin{tabular}{cccc}
\hline Defect $(\mathrm{T})$ & $\mathrm{T}_{\mathrm{Ge}}-\mathrm{V}_{3 \mathrm{Ge}} \mathrm{I}_{\mathrm{T}}$ & $\mathrm{T}_{\mathrm{Ge}}-\mathrm{V}_{2 \mathrm{Ge}} \mathrm{I}_{\mathrm{T}}$ & $\mathrm{T}_{\mathrm{Ge}}-\mathrm{V}_{\mathrm{Ge}} \mathrm{I}_{\mathrm{T}}$ \\
\hline $\mathrm{Cr}$ & -5.53 & -6.12 & -6.25 \\
$\mathrm{Mo}$ & -6.67 & -6.87 & -6.28 \\
$\mathrm{~W}$ & -6.80 & -6.81 & -7.59 \\
$\mathrm{Mn}$ & -8.74 & -10.29 & -9.60 \\
$\mathrm{Fe}$ & -2.85 & -4.53 & -4.63 \\
\hline
\end{tabular}

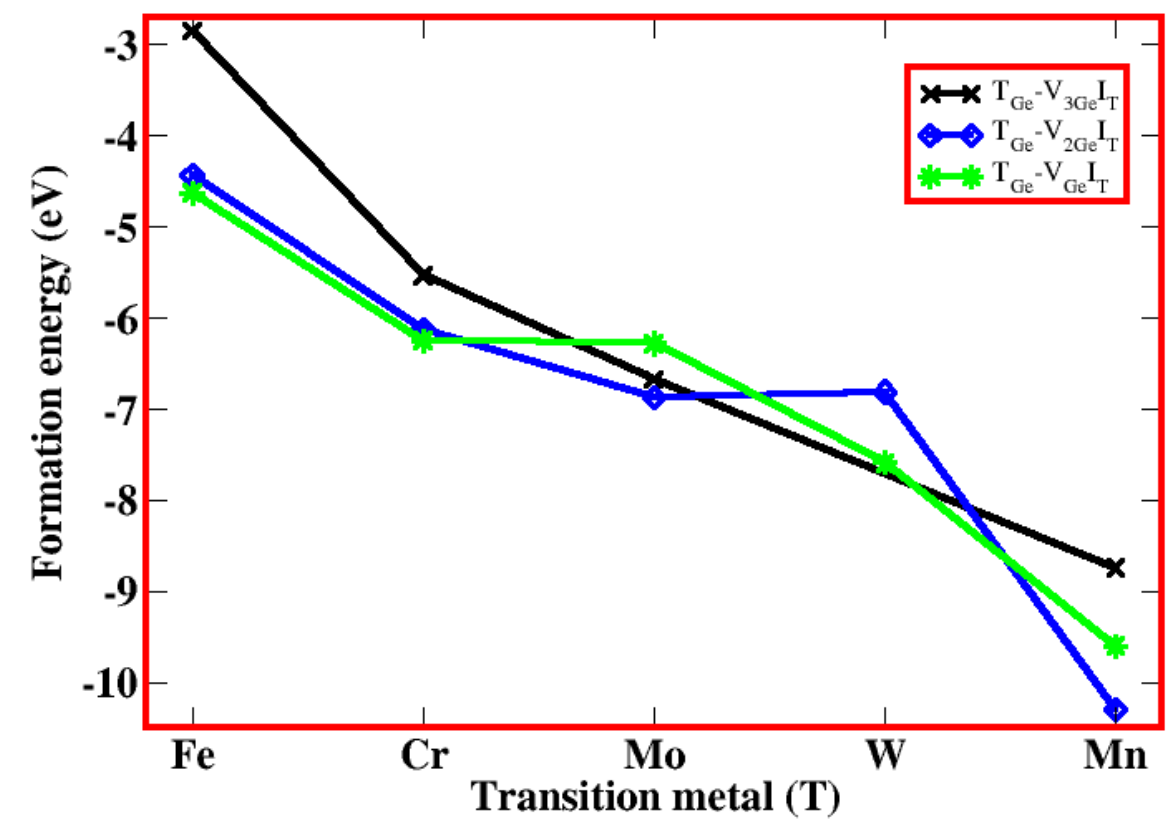

Fig. 2. The plot of formation energy as a function of transition metal.

Stability of transition metals impurity and complexes in Ge

The stability of vacancy-interstitial complexes is well understood from their binding energies $E_{b}$. The result of the binding energies for the $\mathrm{T}_{\mathrm{Ge}^{-}}$ $\mathrm{V}_{n \mathrm{Ge}} \mathrm{I}_{\mathrm{T}}$ is listed in Table 3. Fig. 3 represents the plot of binding energies as a function of the transition metal. According to the definition of the $\mathrm{E}_{\mathrm{b}}$ in Eq. 2 , positive binding energy means that the defect complex can form without dissociation. Based on the definition, we found that for all $\mathrm{T}$ and $\mathrm{n}, \mathrm{T}_{\mathrm{Ge}^{-}}$ $\mathrm{V}_{n \mathrm{Ge}} \mathrm{I}_{\mathrm{T}}$ is positive. The implication of this is that $\mathrm{Cr}$, Mo, W, Mn and Fe impurities form vacancyinterstitial complexes in Ge that are stable. While the W, Cr and Fe related defects are more stable for the $\mathrm{T}_{\mathrm{Ge}}-\mathrm{V}_{\mathrm{Ge}} \mathrm{I}_{\mathrm{T}}$ (as shown in Fig. 3) with bind energies of $6.88,5.07$ and $3.57 \mathrm{eV}$, respectively, the $\mathrm{Mn}$ and $\mathrm{Mo}$ are more stable for the $\mathrm{T}_{\mathrm{Ge}}-\mathrm{V}_{2 \mathrm{Ge}} \mathrm{I}_{\mathrm{T}}$ with binding energies of 5.73 and $5.60 \mathrm{eV}$, respectively. For $\mathrm{Cr}, \mathrm{Mo}, \mathrm{W}, \mathrm{Mn}$ and Fe related defects, the 
difference between the most stable and the next most stable complexes in terms of binding energies are $0.13,0.20,0.78,0.69$ and $0.10 \mathrm{eV}$. This shows that the complex defects under investigation cannot dissociate into smaller fragments, unless at the expense of energy.

Table 3. The predicted binding energies $\left(\mathrm{E}_{\mathrm{b}}\right)$ of $\mathrm{T}_{\mathrm{Ge}}-\mathrm{V}_{n \mathrm{Ge}} \mathrm{I}_{\mathrm{T}}$ (for $\mathrm{n}=1,2$, and 3) vacancy- interstitial complexes in $\mathrm{Ge}$. The $\mathrm{E}_{\mathrm{b}}$ are all in $\mathrm{eV}$.

\begin{tabular}{cccc}
\hline Defect $(\mathrm{T})$ & $\mathrm{T}_{\mathrm{Ge}}-\mathrm{V}_{3 \mathrm{Ge}} \mathrm{I}_{\mathrm{T}}$ & $\mathrm{T}_{\mathrm{Ge}}-\mathrm{V}_{2 \mathrm{Ge}} \mathrm{I}_{\mathrm{T}}$ & $\mathrm{T}_{\mathrm{Ge}}-\mathrm{V}_{\mathrm{Ge}} \mathrm{I}_{\mathrm{T}}$ \\
\hline $\mathrm{Cr}$ & 4.35 & 4.94 & 5.07 \\
$\mathrm{Mo}$ & 5.40 & 5.60 & 5.00 \\
$\mathrm{~W}$ & 6.10 & 5.37 & 6.88 \\
$\mathrm{Mn}$ & 4.18 & 5.73 & 5.04 \\
$\mathrm{Fe}$ & 1.79 & 3.47 & 3.57 \\
\hline
\end{tabular}

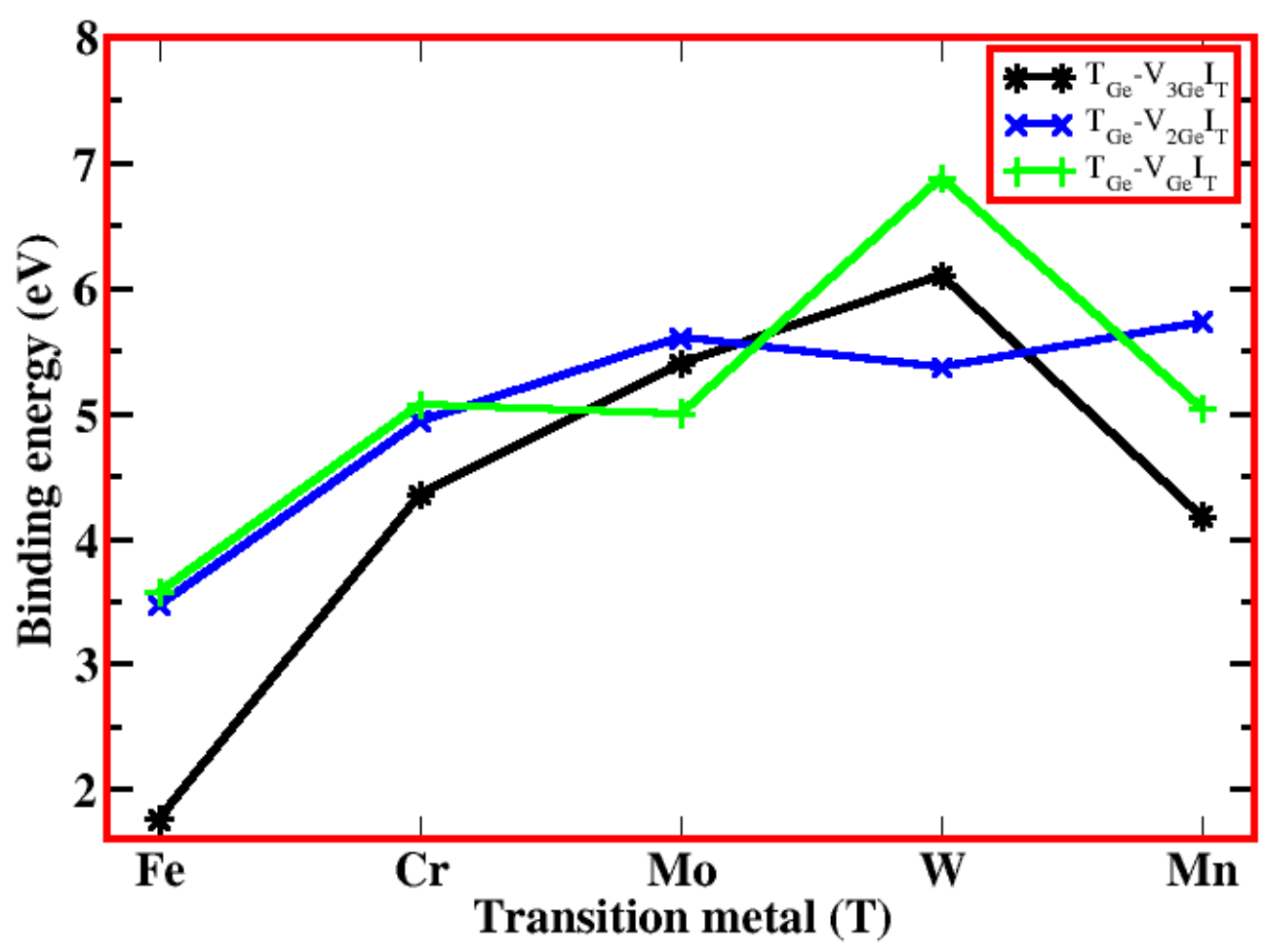

Fig. 3. The plot of binding energies as a function of transition metal.

\section{CONCLUSION}

In conclusion, we have presented DFT ab initio calculated results of interactions between $\mathrm{T}(\mathrm{T}: \mathrm{Cr}$, $\mathrm{Mo}, \mathrm{W}, \mathrm{Mn}$ and $\mathrm{Fe}$ ) vacancy-interstitial complexes in Ge. Our calculations employed projectoraugmented wave (PAW) pseudopotential within the generalized gradient approximation (GGA). The structural property and formation energies of the $\mathrm{T}_{\mathrm{Ge}}-\mathrm{V}_{n G \mathrm{Ge}} \mathrm{I}_{\mathrm{T}}$ for $n=1,2,3$ in the neutral state were obtained. The result of our calculation shown that $\mathrm{T}$ related vacancy-interstitial complexes in $\mathrm{Ge}$ formed with low formation energies between -10.29 and $-2.85 \mathrm{eV}$. For all $\mathrm{T}$, and $n$, the $\mathrm{Mn}$ related a defect complex is energetically most favourable. The stability of $\mathrm{T}_{\mathrm{Ge}}{ }^{-}$ $\mathrm{V}_{n \mathrm{Ge}} \mathrm{I}_{\mathrm{T}}$ defects was also predicted. The calculated binding energy results shown that for all $\mathrm{T}$ and $n$, the Cr, Mn, W, Mo and Fe formed "Frenkel like" complexes that are stable in Ge with binding energies between 1.70 and $6.88 \mathrm{eV}$. The result of this report will provide a frontier insight for experimental investigation of $\mathrm{T}_{\mathrm{Ge}}-\mathrm{V}_{n \mathrm{Ge}} \mathrm{I}_{\mathrm{T}}$ complexes in Ge.

\section{ACKNOWLEDGEMENTS}

This work is based on the research supported partly by National Research foundation (NRF) of South Africa (Grant specific unique reference 
number (UID) 98961). The opinions, findings and conclusion expressed are those of the authors and the NRF accepts no liability whatsoever in this regard. The authors thank the University of Pretoria for computational resources.

\section{REFERENCES}

Blöchl, P.E. 1994. Projector augmented-wave method. Physical review B, 50(24): 17953.

Chi, C. O., Kim, H., McIntyre,P.C. and Saraswat, K.C. 2003. A germanium NMOSFET process integratingmetal gate and improved hi-/splkappa/dielectrics. Electron Devices Meeting, 2003. IEDM'03 Technical Digest. IEEE International, 18311834.

Chroneos, A. 2010. Dopant-vacancy cluster formation in germanium. Journal of Applied Physics, 107(7): 076102.

Chroneos, A. and Bracht, H. 2014. Diffusion of $n$ type dopants in germanium. Applied Physics Reviews, 1(1): 011301.

Chroneos, A., Uberuaga, B.P. and Grimes, R.W. 2007. Carbon, dopant, and vacancy interactions in germanium. Journal of Applied Physics, 102(8): 083707.

Claeys, C. and Simoen E. 2011. Germanium-based technologies: from materials to devices. Elsevier.

Deák, P., Aradi, B., Frauenheim, T., Janzén, E. and Gali, A. 2010. Accurate defect levels obtained from the HSE06 range-separated hybrid functional. Physical Review B, 81(15): 153203.

Derlet, P.M., Nguyen-Manh, D. and Dudarev, S.L. 2007. Multiscale modeling of crowdion and vacancy defects in body-centeredcubic transition metals. Physical Review B, 76(5): 054107.

Fage-Pedersen, J., Larsen, A.N. and Mesli, A. 2000. Irradiation-induced defects in Ge studied by transient spectroscopies. Physical Review B, 62(15): 10116-10125.

Freysoldt, C., Grabowski, B., Hickel, T., Neugebauer, J., Kresse, G., Janotti, A. and Van de Walle, C.G. 2014. First-principles calculations for point defects in solids. Reviews of modernphysics, 86(1):253-305.

Igumbor, E. and Meyer, W.E. 2016. A hybrid functional calculation of $\mathrm{Tm} 3+$ defects in germanium (Ge). Materials Science in SemiconductorProcessing, 43: 129-133.
Igumbor, E., Obodo, K. and Meyer, W.E. 2016. Ab Initio Study of MgSe Self-Interstitial (Mgi and Sei). Solid State Phenomena 242:440-446.

Igumbor, E., Ouma, C.N.M., Webb, G. and Meyer, W.E. 2016. Ab-initio study of germanium di-interstitial using a hybrid functional (HSE). Physica B: Condensed Matter, 480: 191-195.

Istratov, A.A. and Weber, E.R. 2002. Physics of copper in silicon. Journal of The Electrochemical Society, 149(1): G21-G30.

Istratov, A.A., Hieslmair, H. and Weber, E.R. 1999. Iron and its complexes in silicon. Applied Physics A: Materials Science \& Processing, 69(1):13-44.

Kresse, G. and Furthmüller, J. 1996. Efficiency of ab-initio total energy calculations for metals and semiconductors using a planewave basis set. Computational materials science, 6(1): 15-50.

Kresse, G. and Furthmüller, J. 1996. Efficient iterative schemes for ab initio total-energy calculations using a plane-wave basis set. Physical review B, 54(16): 11169.

Kresse, G. and Joubert, D. 1999. From ultrasoft pseudopotentials to the projector augmented-wave method. Physical Review $B$, 59(3): 1758.

Nyamhere, C., Das, M., Auret, F.D. and Chawanda, A. 2008. A study of electron induced defects in n-type germanium by deep level transient spectroscopy (DLTS). PhysicaStatus Solidi (c), 5(2): 623-625.

Perdew, J.P., Burke, K. and Ernzerhof, M. 1996. Generalized gradient approximation made simple. Physical review letters, 77(18): 38653868.

Singh, H.P. 1968. Determination of thermal expansion of germanium, rhodium and iridium by X-rays. Acta Crystallographica Section A: Crystal Physics, Diffraction, Theoretical and General Crystallography, 24(4): 469-471.

Zhang, S.B. and Northrup, J.E. 1991. Chemical potential dependence of defect formation energies in GaAs: Application to Ga selfdiffusion. Physical review letters, 67(17): 2339.

Zollo, G., Lee, Y.J. and Nieminen, R.M. 2004. Properties of intrinsic di-interstitials in GaAs. Journal of Physics: Condensed Matter 16(49): 8991. 